\title{
Formación de Directivos Escolares en Chile: Situación Actual, Evolución y Desafíos de su Oferta
}

\author{
Preparation of School Leaders in Chile: Current Situation, \\ Evolution and Challenges
}

\author{
Gonzalo Muñoz ${ }^{1 *}$ \\ Josefina Amenábar 1 \\ María José Valdebenito ${ }^{2}$ \\ ${ }^{1}$ Universidad Diego Portales, Chile \\ ${ }^{2}$ Universidad Alberto Hurtado, Chile
}

\begin{abstract}
El artículo describe la situación actual de la formación de directivos escolares en Chile, a través de una caracterización de los programas de máster especializados en esta área y de su comparación con una observación inicial realizada en el año 2010. Se utilizan como fuente principal los resultados de un cuestionario aplicado a los responsables de una muestra de los programas de formación vigentes en Chile al año 2017. La evidencia recopilada permite concluir que la preparación de directivos en Chile ha experimentado un importante cambio curricular, consistente con las políticas educacionales en este país. Esto se ha traducido en una mayor priorización de conocimientos y habilidades como la teoría y práctica del liderazgo educativo, herramientas para el mejoramiento escolar o la gestión del desarrollo profesional docente. Este interesante cambio convive, sin embargo, con un evidente estancamiento a nivel metodológico: sigue predominando un modelo formativo esencialmente teórico y carente de instancias prácticas de desarrollo profesional, lo que limita las posibilidades de que esta formación logre impactar sustantivamente en el aprendizaje y desempeño de los líderes escolares. El caso chileno entrega, a nivel de la formación misma pero también de las políticas que la promueven, aprendizajes relevantes para el desafío de formar con calidad a los líderes escolares de América Latina.
\end{abstract}

Descriptores: Liderazgo; Administrador de la educación; Gestión educacional; Formación; Política educacional.

The article describes the current situation of the preparation of school leaders in Chile, through a characterization of the master's programs specialized in this area and their comparison with an initial observation made in 2010. The main source was the results of a questionnaire applied to the people responsible for a sample of the training programs in force in Chile in 2017. The evidence gathered allows us to conclude that the preparation of school leaders in Chile has experienced an important curricular change, consistent with educational policies in this country. This has resulted in a greater prioritization of knowledge and skills such as the theory and practice of educational leadership, tools for school improvement or the management of professional teacher development. This interesting change coexists, however, with a clear stagnation at a methodological level: an essentially theoretical training model still prevails, and the programs lack practical instances of professional development, which limits the possibilities that this training will have a substantive impact on the learning and performance of the school leaders. The Chilean case provides, at the level of the training and preparation but also the policies that promote it, relevant learning for the challenge of preparing with quality school leaders in Latin America.

Keywords: Leadership; Educational administrators; Educational management; Training; Educational policy.

*Contacto: gonzalo.munozs@mail.udp.cl

ISSN: 1696-4713

www.rinace.net/reice/

revistas.uam.es/reice
Recibido: 5 de noviembre 2018

$1^{\text {a }}$ Evaluación: 11 de febrero 2019

$2^{\text {a }}$ Evaluación: 26 de febrero 2019

Aceptado: 8 de marzo 2019 


\section{Introducción}

Es ampliamente reconocido en el mundo educacional que los líderes educativos constituyen un actor central para la mejora escolar y el aprendizaje de los estudiantes (Darling-Hammond et al., 2009; Huber, 2006; Leithwood y Jantzi, 2000; Murillo, 2006). En este marco, en muchas partes se han ampliado las funciones y atribuciones de los directivos escolares (Cobb, Weiner y Gonzales, 2016; Darling-Hammond et al., 2009; Pont, Nusche y Moorman, 2008; Schleicher, 2012) al mismo tiempo que se ha desarrollado una vasta reflexión sobre la formación de estos líderes, debido a su centralidad para potenciar las capacidades de esta estratégica función (Gómez, Rodríguez y López, 2014; Huber, 2006; Pont, Nusche y Moorman, 2008; Young, 2019). En vista de lo anterior, en muchos países, el desarrollo de líderes escolares es una prioridad en la agenda de políticas educacionales (Bush, 2019; Huber, 2006; Schleicher, 2012).

Chile representa un caso interesante en este ámbito, tanto debido a que el país ya cuenta con una cierta trayectoria de iniciativas formativas para líderes escolares como al hecho de que el sistema educativo chileno se encuentra actualmente implementando un conjunto de transformaciones sustantivas (Treviño, 2018; Weinstein, Azar y Flessa, 2018) que están tensionado la función directiva ${ }^{1}$, invitándola a traducir cada uno de los cambios en curso en oportunidades concretas de mejoramiento del trabajo de sus unidades educativas, lo que a su vez desafía a la formación de estos actores. Junto con lo anterior, Chile es también un caso relevante debido a que ya se ha venido acumulado alguna evidencia sobre la calidad promedio de la oferta misma y su (in)capacidad para responder adecuadamente a lo que los líderes escolares necesitan (Muñoz y Marfán, 2011 ; Weinstein, Azar y Flessa, 2018).

En este escenario, el presente artículo busca contribuir al debate internacional sobre la formación de directivos, describiendo la situación actual de la oferta formativa en Chile y analizando su capacidad para responder a los desafíos que la experiencia internacional ha venido relevando en el último tiempo. A la hora de describir la experiencia chilena se da cuenta, entre otras variables, del alcance de la oferta, de quienes son los destinatarios de la formación, de los contenidos que aborda y de las principales metodologías que emplea. El foco del artículo son los programas de Máster especializados en formar directivos escolares y que se encontraban vigentes en Chile al año 2017. Los datos recogidos -a través de una encuesta a los encargados de los programas-permiten comparar la situación actual de la formación de directivos con la de comienzos de la misma década (Muñoz y Marfán, 2011).

El artículo se organiza de la siguiente manera. Primero, se sintetiza la literatura reciente en este tema, lo que permite identificar los principales aprendizajes que la experiencia internacional sobre formación de directivos escolares ha venido acumulando. En segundo lugar, se describe la evidencia disponible en Chile sobre formación de directivos, contexto en el cual se inserta la nueva información que esta investigación provee. En tercer término,

\footnotetext{
${ }^{1}$ Es así como hoy, por ejemplo, los directivos escolares tendrán un rol clave en la implementación del nuevo sistema de desarrollo profesional docente (orientando el uso de las horas no lectivas y los planes de desarrollo que cada profesor deberá diseñar e implementar), en la ley de inclusión (recibiendo nuevos recursos, ejecutando planes de apoyo a la inclusión y ajustando distintos procedimientos de la escuela a la nueva normativa) y en la nueva educación pública (desempeñando derechamente nuevas funciones, como la selección directa de docentes, la participación en instancias colaborativas o la administración directa de una parte de los recursos financieros de la escuela). Todas estas leyes son de aplicación reciente. Un detalle de ellas y su afectación a la función directiva puede encontrarse en Weinstein et al., 2018.
} 
se describe la metodología y el plan de análisis de los resultados. En cuarto lugar, se presentan los principales resultados del estudio, caracterizando la oferta formativa existente en Chile. Finalmente, se sintetizan los principales resultados y se proponen algunos desafíos para el desarrollo de futuras investigaciones y políticas públicas en esta agenda.

\section{Antecedentes generales: La relevancia de la formación de líderes escolares}

El liderazgo escolar puede conceptualizarse como el conjunto de prácticas que despliegan los líderes de una organización, que contribuyen a generar un sentido y visión compartida en el centro educativo, que a su vez influye y moviliza el comportamiento de sus miembros, con el objetivo de mejorar el aprendizaje de sus estudiantes (Leithwood y Jantzi, 2000; Marzano, Waters y McNulty, 2005). Hace ya más de una década que la investigación educacional ha venido demostrando la relevancia de este factor, concluyendo que se trata de la segunda variable más influyente en el logro de los aprendizajes de los estudiantes, después del desempeño de los docentes en la sala de clases. Se trata de un efecto que se ejerce indirectamente a través de la influencia que desarrollan los directivos para mejorar el trabajo que realizan los docentes en el aula (Leithwood, Harris y Hopkins, 2008; Marzano, Waters y McNulty, 2005).

Esta evidencia sobre la relevancia del liderazgo escolar ha convivido con nuevas demandas a los líderes de los centros educativos, de quienes se espera no se restrinjan a la administración de los establecimientos, sino que más bien sean líderes de procesos de cambio con el fin de lograr mejoras continuas en el aprendizaje de sus estudiantes (Cobb, Weiner y Gonzales, 2016; Darling-Hammond et al., 2009; Huber, 2006; Murillo, 2006). En este sentido, la investigación reciente ha ido identificando un conjunto de prácticas que favorecen los aprendizajes y antes de eso generan condiciones para el trabajo pedagógico y la calidad de la enseñanza (Leithwood y Jantzi, 2005; Marzano, Waters y McNulty, 2005; Robinson, Lloyd y Rowe, 2008). En esa misma dirección, varios países han definido estándares o marcos orientadores respecto a lo que se espera de los líderes escolares (Muñoz, 2018; Schleicher, 2012; Young, 2019).

De esta forma, en los sistemas educativos de todo el mundo hoy ya existe una cierta orientación general sobre lo que significa liderar para la mejora escolar (Hitt y Tucker, 2016). En este escenario, una pregunta central que se han hecho los investigadores y policy makers durante la última década) ha sido cómo formar y desarrollar capacidades en los directivos escolares para que efectivamente puedan ampliar su repertorio de prácticas y conduzcan a los profesores y a toda la comunidad educativa hacia el logro de los aprendizajes esperados (Bush, 2019; Orr y Orphanos, 2011; Pont, Nusche y Moorman, 2008; Wallace Foundation, 2016).

En vista de lo anterior, en muchos países, el desarrollo de líderes escolares es una prioridad en la agenda de políticas educacionales (Bush, 2019; Huber, 2006; Schleicher, 2012;). Es así como se han ido estableciendo requerimientos formativos para alcanzar el cargo de director de escuela, al mismo tiempo que se ha ampliado la oferta de formación que permite ir alcanzando dichas exigencias (Bush, 2019; Orphanos y Orr, 2014; Pont, Nusche y Moorman, 2008). 
La forma en la que los países han decidido enfrentar la formación de los directores y directivos de escuela muestra una alta heterogeneidad (Huber, 2006; Muñoz, 2018; Schleicher, 2012). Mientras en algunos países la formación es obligatoria y provista por pocas instituciones formadoras, en otros existe una variada oferta formativa impartida por proveedores en competencia, que responden a ciertas regulaciones nacionales o estaduales. Para Huber (2006), es evidente que sólo es posible asegurar ciertos niveles de calidad en los programas formativos en la medida que algún nivel central defina ciertos márgenes y exigencias básicas. Sin embargo, se debe tener en consideración que la literatura y experiencia reciente también ha ido poniendo énfasis en cuestionar la excesiva estandarización de lo que el mundo educacional entiende por prácticas efectivas de liderazgo y sus aplicaciones a la formación (Qian, Walker y Bryant, 2017; Oplatka, 2017). Una aplicación descontextualizada de dichas claves puede conducir a una lectura errónea del fenómeno del liderazgo, tanto a nivel de la investigación como de la preparación de directivos.

La literatura y experiencia internacional permiten identificar distintos momentos y etapas en las que se desarrolla la formación de los líderes educativos. Es así como es posible encontrar -sobre todo en sistemas educativos con más desarrollo en esta área- una complementariedad entre múltiples tipos de formación de liderazgo: existen programas para quienes aún no asumen un cargo directivo (formación inicial), para quienes están empezando su función (programas de inducción), y para aquellos profesionales directivos en ejercicio en busca de formación continua (Darling-Hammond et al., 2009; Huber, 2006; Pont, Nusche y Moorman, 2008; Slater, García y Mentz, 2019). Literatura reciente ha relevado también la necesidad de formar específicamente a aquellos profesionales de la educación que pueden cumplir funciones de asesoría y apoyo al desarrollo de otros líderes a través de diversas vías, como la mentoría o el coaching (Aas y Fluckiger, 2016; Bush, 2019; Oliva-Rodríguez y López-Yáñez, 2019; Poggi, 2019).

Más allá de la diversidad de políticas y modelos formativos, una revisión sistemática de la literatura especializada -que ha puesto foco en la preparación de calidad y con buenos resultados- permite identificar algunos consensos relevantes sobre las características fundamentales de los programas de formación. En el cuadro 1 se describen los aspectos medulares de estas "buenas prácticas" en materia de formación de líderes escolares.

Al mismo tiempo que la evidencia permite identificar ciertos aspectos clave de la formación de directivos para orientar su mejora, lo cierto es que existe un cierto consenso en el mundo académico respecto a que la mayoría de los programas formativos hoy no responde adecuadamente a estos desafíos y, más importante aún, dicha formación no está logrando impactar eficazmente en el trabajo de los directivos escolares. Como resultado, una parte importante de los directores y directivos no se estarían preparando adecuadamente para las demandas que hoy los sistemas escolares imponen a sus líderes (Darling Hammond et al., 2009; Gómez, Rodríguez y López, 2014; Jackson y Kelley, 2002; Reyes-Guerra y Barnett, 2017). 
Cuadro 1. Características principales de experiencias efectivas de formación de directivos

\begin{tabular}{|c|c|c|}
\hline CARACTERÍSTICAS & DESCRIPCIÓN & FUENTES \\
\hline $\begin{array}{l}\text { Objetivos } \\
\text { centrados en la } \\
\text { mejora escolar }\end{array}$ & $\begin{array}{l}\text { Los programas formativos deben tener } \\
\text { objetivos orientados al aprendizaje de los } \\
\text { estudiantes y la mejora escolar. El } \\
\text { desarrollo de competencias relacionadas } \\
\text { al liderazgo pedagógico es indispensable. }\end{array}$ & $\begin{array}{l}\text { Darling-Hammond y otros } \\
\text { (2009), Fluckiger, Lovett y } \\
\text { Dempster (2014), Pont, } \\
\text { Nusche y Moorman (2008) } \\
\text { y Schleicher (2012). }\end{array}$ \\
\hline $\begin{array}{l}\text { Contenidos } \\
\text { acordes a las } \\
\text { demandas } \\
\text { directivas }\end{array}$ & $\begin{array}{l}\text { Los contenidos y enfoques de un programa } \\
\text { deben estar en sintonía con las funciones } \\
\text { y responsabilidades que actualmente se } \\
\text { demanda a los líderes escolares, } \\
\text { distinguiendo los conocimientos } \\
\text { necesarios para las distintas etapas de la } \\
\text { carrera directiva y siendo atingentes al } \\
\text { contexto de cada sistema escolar. }\end{array}$ & $\begin{array}{l}\text { Darling-Hammond y otros } \\
\text { (2009), Dempster y otros } \\
\text { (2019), Fluckiger, Lovett y } \\
\text { Dempster (2014), Huber } \\
\text { (2006), Jackson y Kelley, } \\
\text { (2002), Pont, Nusche y } \\
\text { Moorman (2008) y } \\
\text { Schleicher (2012). }\end{array}$ \\
\hline $\begin{array}{l}\text { Congruencia con } \\
\text { los procesos del } \\
\text { sistema escolar }\end{array}$ & $\begin{array}{l}\text { En línea con la práctica anterior, los } \\
\text { programas deben adoptar una perspectiva } \\
\text { sistémica, alineando sus contenidos y } \\
\text { metodologías con estándares y objetivos } \\
\text { estatales o locales y procesos más amplios } \\
\text { del sistema escolar. }\end{array}$ & $\begin{array}{l}\text { Darling-Hammond y otros } \\
\text { (2009), Fluckiger, Lovett y } \\
\text { Dempster (2014), Jackson } \\
\text { y Kelley (2002), Pont, } \\
\text { Nusche y Moorman, (2008) } \\
\text { y Schleicher (2012), }\end{array}$ \\
\hline Admisión selectiva & $\begin{array}{l}\text { Los programas de formación deben tener } \\
\text { cuidadosos procesos de selección, } \\
\text { tomando en consideración la experiencia } \\
\text { como maestros, el compromiso con la } \\
\text { mejora educacional y el potencial } \\
\text { liderazgo de los postulantes. }\end{array}$ & $\begin{array}{l}\text { Darling-Hammond y otros } \\
\text { (2009), Fluckiger, Lovett y } \\
\text { Dempster (2014), Jackson } \\
\text { y Kelley (2002), Pont, } \\
\text { Nusche y Moorman (2008), } \\
\text { Schleicher (2012) y } \\
\text { Wallace Foundation } \\
\text { (2016). }\end{array}$ \\
\hline $\begin{array}{l}\text { Construcción de } \\
\text { redes de apoyo }\end{array}$ & $\begin{array}{l}\text { Es importante fomentar la construcción de } \\
\text { redes de apoyo y trabajo en equipo, } \\
\text { durante y después del programa, ya que } \\
\text { enriquece su proceso formativo. } \\
\text { Incorporación de coaching grupales. Una } \\
\text { estructura de cohortes facilita estas redes. }\end{array}$ & $\begin{array}{l}\text { Darling-Hammond y otros } \\
\text { (2009), Fluckiger, Lovett y } \\
\text { Dempster (2014), Pont, } \\
\text { Nusche y Moorman (2008), } \\
\text { Schleicher (2012) y } \\
\text { Wallace Foundation (2016) }\end{array}$ \\
\hline $\begin{array}{l}\text { Asociación con } \\
\text { instituciones } \\
\text { externas }\end{array}$ & $\begin{array}{l}\text { Establecer lazos de colaboración y } \\
\text { asociación entre universidades, gobiernos } \\
\text { locales u otras instituciones es relevante, } \\
\text { ya que impacta positivamente en los } \\
\text { estudiantes y sus escuelas, en la medida } \\
\text { que expanden sus redes de apoyo a } \\
\text { diferentes actores, los programas se } \\
\text { vuelven más coherentes con los procesos } \\
\text { locales y nacionales, y se facilita la } \\
\text { formación práctica de los estudiantes. }\end{array}$ & $\begin{array}{l}\text { Darling-Hammond y otros } \\
\text { (2009) y Fluckiger, Lovett } \\
\text { y Dempster (2014). }\end{array}$ \\
\hline $\begin{array}{l}\text { Integración } \\
\text { teórico-práctica }\end{array}$ & $\begin{array}{l}\text { Se vuelve necesario que los programas } \\
\text { integren y establezcan una clara } \\
\text { coherencia entre la formación teórica y } \\
\text { práctica, con el fin de desarrollar la } \\
\text { capacidad de llevar a la realidad laboral } \\
\text { de los estudiantes los conocimientos } \\
\text { adquiridos. }\end{array}$ & $\begin{array}{l}\text { Darling-Hammond y otros } \\
\text { (2009), Fluckiger, Lovett y } \\
\text { Dempster (2014) y Wallace } \\
\text { Foundation (2016). }\end{array}$ \\
\hline $\begin{array}{l}\text { Fuertes } \\
\text { experiencias } \\
\text { clínicas con foco } \\
\text { en desarrollo de } \\
\text { capacidades }\end{array}$ & $\begin{array}{l}\text { Para una mejor integración teórico- } \\
\text { práctica y mayor pertinencia del } \\
\text { programa a los contextos de los } \\
\text { directivos, es necesaria la presencia de } \\
\text { espacios prácticos formales (pasantías), } \\
\text { con la tutoría de expertos o profesores }\end{array}$ & $\begin{array}{l}\text { Darling-Hammond y otros } \\
\text { (2009), Fluckiger, Lovett y } \\
\text { Dempster (2014), Jackson } \\
\text { y Kelley (2002), Huber, } \\
\text { (2006), Pont, Nusche y } \\
\text { Moorman (2008), Reyes- }\end{array}$ \\
\hline
\end{tabular}




\begin{tabular}{|c|c|c|}
\hline & $\begin{array}{l}\text { con experiencia para guiar el trabajo, } \\
\text { resolver interrogantes, y ser parte } \\
\text { fundamental de la retroalimentación a los } \\
\text { estudiantes. }\end{array}$ & $\begin{array}{l}\text { Guerra y Barnett (2017), } \\
\text { Schleicher (2012) y } \\
\text { Wallace Foundation } \\
(2016) \text {. }\end{array}$ \\
\hline $\begin{array}{l}\text { Docentes con } \\
\text { amplia } \\
\text { experiencia y } \\
\text { calidad probada }\end{array}$ & $\begin{array}{l}\text { El equipo docente de un programa es un } \\
\text { elemento esencial para garantizar su } \\
\text { calidad. Se requiere una mayoría de } \\
\text { profesores con experiencia práctica y un } \\
\text { sólido manejo de contenidos asociados al } \\
\text { liderazgo escolar. }\end{array}$ & $\begin{array}{l}\text { Darling-Hammond y otros } \\
\text { (2009), Hackmann y } \\
\text { McCarthy (2011), Young y } \\
\text { Crow (2016) y Young y } \\
\text { otros (2009). }\end{array}$ \\
\hline $\begin{array}{l}\text { Procesos de } \\
\text { mejora continua }\end{array}$ & $\begin{array}{l}\text { Para mantener la calidad de los programas } \\
\text { formativos, se vuelve fundamental la } \\
\text { presencia de procesos formales para su } \\
\text { mejora continua. Se requiere que estos } \\
\text { procesos se basen en una evaluación } \\
\text { integral, abarcando tanto métodos de } \\
\text { enseñanza y gestión de las acciones } \\
\text { formativas, así como también los efectos } \\
\text { en el aprendizaje y trayectoria profesional } \\
\text { de sus estudiantes. }\end{array}$ & $\begin{array}{l}\text { Fluckiger, Lovett y } \\
\text { Dempster (2014) y Wallace } \\
\text { Foundation (2016). }\end{array}$ \\
\hline
\end{tabular}

Nota: Los libros y artículos seleccionados para esta revisión responden a dos tipos de evidencia. Por un lado, se consideran investigaciones que evalúan un amplio número de programas de formación, y por otro, se encuentran estudios que se basan en un meta análisis de artículos y libros sobre el tema.

Fuente: Elaboración propia en base a Revisión sistemática de libros y artículos especializados.

A pesar de este diagnóstico crítico, la investigación reciente también ha identificado algunos cambios y avances importantes. Así, por ejemplo, se ha ido transitando desde un enfoque más centrado en aspectos administrativos y legales, hacia uno centrado en las competencias para el liderazgo y la mejora escolar centrada en los aprendizajes. Por otro lado, también es posible afirmar que los programas y acciones formativas dirigidas a directivos cada vez dan una mayor preponderancia a la formación práctica, al acompañamiento de mentores y al trabajo en red entre líderes, por su impacto positivo en los participantes y en las escuelas que se benefician de estas experiencias prácticas (Huber, 2006; Oliva-Rodríguez y López-Yáñez, 2019; Reyes-Guerra y Barnett, 2017; RincónGallardo, 2019; Weinstein et al., 2015). Estos avances se explicarían en parte porque crecientemente muchos programas de formación han estado recogiendo más rigurosamente los conocimientos recientes sobre el aprendizaje de adultos, como la necesidad de anclar los nuevos conocimientos a experiencias pasadas, la importancia de partir siempre desde las necesidades y problemas de la práctica concreta o lo significativo que resulta que los directivos se constituyan en gestores de su propio aprendizaje (Huber, Skedsmo y Schwander, 2019; Young, 2019).

\section{Formación de directivos en Chile y América Latina}

Si bien la mayoría de los países de América Latina no ha logrado consolidar políticas sistémicas orientadas al fortalecimiento del liderazgo escolar², es claro que la formación de directivos escolares ha ido transformándose también en una prioridad de los países de

${ }^{2}$ En este plano, los esfuerzos se han concentrado hasta el momento principalmente en precisar las responsabilidades de los directores y directivos y de crear sistemas de selección profesionales y transparentes (Weinstein et al., 2015) 
la región (Weinstein et al., 2015). Esto se puede confirmarse a través de algunos estudios recientes, que muestran que cerca del $50 \%$ de los directores en la región tiene un título universitario (con una amplia variación entre países, debido a las diferentes normativas sobre la formación de maestros y también las exigencias para ser director) y que cerca de un 20\% tiene estudios especializados de posgrado (Murillo, 2012; Weinstein, Azar y Flessa, 2018). Este enorme esfuerzo que los países están haciendo en materia de formación de líderes escolares en América Latina convive sin embargo con evidencia que indica que la calidad de los programas es altamente desigual y en promedio baja. Existe un predominio de programas altamente tradicionales, con un sello más bien academicista, con poca presencia de experiencias prácticas y sin diferenciar las diferentes etapas de la carrera directiva, lo que disminuye su potencial efecto en las prácticas de liderazgo. Esta debilidad relativa tiene que ver sin duda con la inexistencia de políticas que aseguren que la formación de directivos responda a las necesidades de formación -nacionales y locales- y cumpla con ciertas exigencias básicas de calidad (Weinstein et al., 2015).

Chile, por su parte, se posiciona como uno de los países de la región que mayor espacio le ha dado a la formación especializada de directivos (Donoso et al., 2012; Muñoz, 2018). La legislación en el país establece, desde comienzos de la década de los 90, que para poder acceder al cargo de director (a través de un concurso en el caso de los centros educativos públicos) los profesores deben poseer una especialización en gestión directiva lo que provocó que los profesionales interesados en la dirección escolar iniciaran procesos formales de formación, en algunos casos individualmente y en otros con apoyo de sus administradores o "sostenedores". Este impulso "de abajo hacia arriba" ha convivido, desde el año 2011, con la implementación de un plan de formación de directores ${ }^{3}$, impulsado directamente por el estado para desarrollar las capacidades de los líderes del sistema escolar público y privado con financiamiento estatal. Como consecuencia de ese recorrido, según algunas cifras nacionales y también algunos estudios comparados, cerca de un $80 \%$ de los directivos -principalmente directores y jefes de UTP (coordinadores académicos en Chile)- posee algún postgrado, mientras que más del 50\% tiene el grado de máster, la mayoría de ellos especializados en el área del liderazgo y la gestión educativa (FOCUS, 2016; Muñoz y Marfán, 2011).

Evidentemente, este esfuerzo de formación de los líderes escolares se enmarca dentro de una política educativa más general que ha ido dando cada vez más centralidad a los directores y directivos escolares (Weinstein y Muñoz, 2012). La concursabilidad para los cargos de director en el sector público (establecida en el año 2005), la definición eminentemente pedagógica de su función en la legislación (fijada en la Ley General de Educación, del año 2009), la actualización del Marco para la Buena Dirección (realizado recientemente y publicado el año $2015^{4}$ ) y la creación de dos Centros de Liderazgo (que en una primera fase de trabajo cubren el período 2016-2019) son pasos concretos en esa dirección. Todas estas iniciativas convergen en el objetivo de fortalecer las capacidades de los directivos escolares para, a través de ello, movilizar el cambio y la mejora escolar. En

\footnotetext{
${ }^{3}$ El Plan de Formación de Directores consiste en que el Ministerio de Educación financia la preparación en diferentes programas impartidos por universidades y centros de formación, diferenciando actualmente programas por la etapa de la trayectoria en la que se encuentran y los niveles experiencia de los participantes. El promedio de inversión anual es superior a los 4 millones de dólares, obteniendo un total invertido entre el año 2011 y 2018 de aproximadamente 45 millones de dólares.

${ }^{4}$ El detalle de este marco orientador puede encontrarse en https://liderazgoescolar.mineduc.cl/marco-para-la-buenadireccion-y-el-liderazgo-escolar/
} 
el último tiempo estas iniciativas han comenzado a convivir con nuevos marcos normativos (como la Ley de Inclusión o la Carrera Docente), que van también exigiendo a la función directiva nuevas responsabilidades (Weinstein, Muñoz y Rivero, 2018). Además, otra ley, que crea un Nuevo Sistema de Educación Pública y que recientemente ha comenzado a implementarse, amplía las atribuciones de los directores y fortalece su posición general en el marco de las decisiones críticas de los establecimientos educacionales (Bellei, 2018).

Ahora bien, aun cuando el Estado chileno ha ido poniendo cada vez un foco mayor en la formación de directivos escolares, existe muy poca información sobre la calidad de dicha oferta, su pertinencia y, por cierto, sobre la efectividad de la misma. Un estudio empírico realizado en el año 2010 , permitió identificar que en el país existían cerca de 80 programas de formación dirigidos a la función directiva, presenciales y con una duración de más de un año. El estudio sirvió para dar cuenta de una oferta altamente homogénea (en cuanto a contenidos y métodos), desconectada con las necesidades específicas de cada fase de las trayectorias de los directivos, con escaso foco en el liderazgo propiamente pedagógico y con muy poca presencia de experiencias prácticas. Estas características de la formación estarían explicando, además -al menos en parte- la nula correlación que posee el tipo de grado obtenido por los directores en Chile (diplomado, máster o doctorado) con sus prácticas de liderazgo efectivo y los resultados de los estudiantes de sus escuelas (Muñoz y Marfán, 2011). A una conclusión similar llegan Weinstein, Azar y Flessa (2018), ahora no solo para Chile, sino que para 7 países de la región.

En síntesis, la evidencia con la que se cuenta para Chile demostraba hacia comienzos de esta década que el desafío de la formación de directores y directivos escolares no se encuentra en la existencia y disponibilidad de una oferta especializada en los directivos (como sí ocurre en algunas latitudes), pero sí en su pertinencia y calidad. Impulsar una agenda de calidad de la formación de los líderes educativos supone contar con un nuevo diagnóstico de dicha formación, que vaya complementándose con evidencia respecto a los efectos que esta preparación tiene en las prácticas y trayectorias de los directivos. Los resultados del estudio que aquí se presentan avanzan en esa dirección.

\section{Métodos y fuentes de información}

En el contexto de los antecedentes ya presentados, este estudio tiene como objetivo describir y analizar la oferta formativa de postgrado existente actualmente para los directivos escolares. Para ello se utilizó una metodología cuantitativa, que consistió en la aplicación de cuestionarios estructurados al universo de responsables de los programas de máster vigentes en Chile, que se desarrollan durante al menos durante un año calendario y cuyo foco explícito es la preparación de directivos escolares.

La construcción del universo de programas se realizó por medio de un catastro basado en información secundaria disponible y la revisión de los sitios web de las universidades públicas y privadas que ofrecen estos programas de máster. Como resultado se identificaron 45 programas vigentes de formación de directivos para el año 2017 (cuadro A 1 del anexo). Los datos fueron recogidos entre los meses de junio y septiembre del año 2017. Se aplicó un cuestionario estructurado online (con seguimiento telefónico) al 
director o coordinador académico de cada programa ${ }^{5}$, obteniendo una tasa de respuesta cercana al 80\%, lo que implica que se obtuvo información directa de 35 programas.

Los contenidos de la encuesta buscaron dar cuenta de distintas características institucionales y de implementación de los programas de formación. Entre los ámbitos de indagación se consideraron las características de generales de los programas (composición, antigüedad, certificación/ acreditación y otros), sus contenidos curriculares, sus estrategias metodológicas, sus mecanismos de monitoreo de aprendizajes o resultados y su disposición a implementar distintos mecanismos de evaluación.

Cabe señalar que el instrumento consideró entre sus preguntas algunas variables similares a las utilizadas por un estudio-catastro realizado por Muñoz y Marfán (2011) durante el año 2010. Su incorporación tuvo como propósito realizar un análisis de la evolución de las características de la oferta formativa, lo que permitiría identificar los cambios experimentados por dicha oferta. $\mathrm{El}$ análisis de la información recopilada se inició con la construcción de una matriz o base de datos que integró toda la data disponible y levantada primariamente sobre la oferta formativa vigente. Sobre esa base, y utilizando el programa estadístico SPSS, se realizó el análisis descriptivo sintetizado en este artículo.

\section{Resultados: Características de la formación de directivos en Chile}

\subsection{Aspectos generales de la oferta formativa y sus estudiantes}

Como ya se adelantó, el catastro realizado arrojó que existen 45 programas de máster vigentes que poseen como tienen como propósito explícito formar directivos en el área de liderazgo y gestión escolar. Estos programas son impartidos por 27 instituciones o universidades. 23 de ellas son de carácter privado y 4 público ${ }^{6}$. La mayoría de los programas posee una modalidad presencial (73\%), y un segmento bastante menor una modalidad semipresencial o a distancia ( $20 \%$ y $7 \%$ respectivamente).

La oferta formativa disponible ha aumentado a lo largo del tiempo, en especial en los últimos 5 años. Esto se puede observar a través de los años de antigüedad de los programas estudiados. El 38\% de éstos tiene 5 años o menos de existencia, el 35\% entre 6 y 10 años, mientras que el $26 \%$ tiene más de 10 años. Si bien se trata de una oferta relativamente dinámica, existe una predominancia de programas que han venido acumulando una experiencia importante. En cuanto a los egresados, el estudio permite pesquisar que casi un 60\% de los programas tiene más de 100 egresados en total, cifra que varía de acuerdo a los años de funcionamiento de los mismos. La figura 1 relaciona la antigüedad del programa y el número de egresados, apreciándose una clara asociación entre ambas características. De acuerdo al estudio, el número de egresados por programa al año es de aproximadamente 18 profesionales, lo que implica que cerca de 800 personas

\footnotetext{
${ }^{5}$ En este sentido, la principal limitación de este estudio particular consiste en que los datos proceden de los responsables de los programas y no de los usuarios de estos. Otro estudio actualmente en curso -de los mismos autores- indaga en los efectos que esta formación ha tenido en las prácticas de los directivos escolares, en base a información proporcionada por los ex estudiantes de dichos programas.

${ }^{6}$ Este dato es relevante en tanto demuestra que la inmensa mayoría de los programas de formación de directivos en Chile está siendo provisto por el sector privado. Esto es consistente con la realidad de la formación de Postgrado en el país, donde solo un $30 \%$ de la matrícula se encuentra en universidades públicas. El área de educación representa cerca de un $22 \%$ del total de la matrícula de postgrado en el año 2017 , con cerca de 4.000 estudiantes.
} 
egresan anualmente de los másteres especializados sobre liderazgo y gestión escolar que existen en Chile?

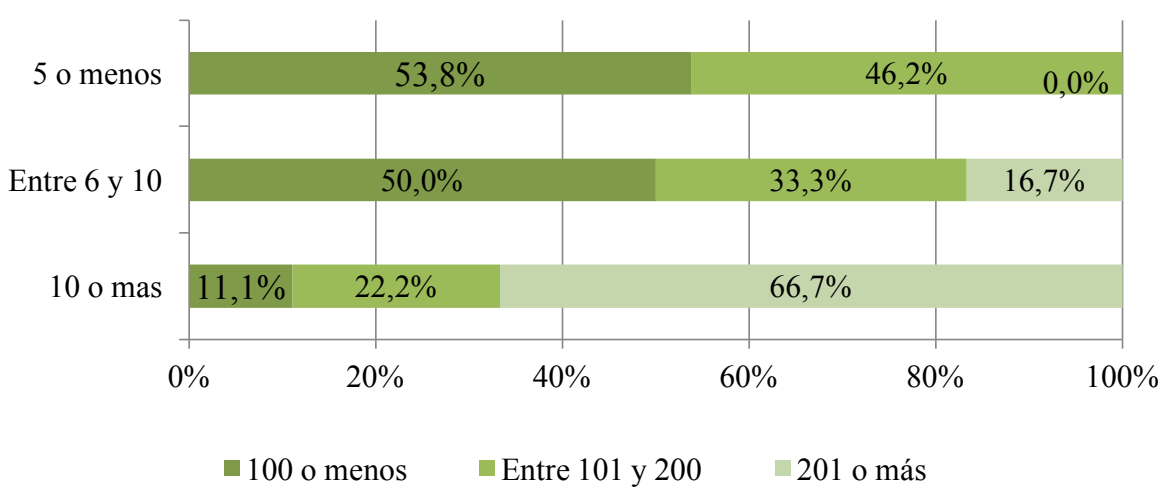

Figura 1. Número de estudiantes egresados según años antigüedad del programa Fuente: Elaboración propia en base a encuesta a encargados Programas de Máster 2017.

Más allá de la diversidad de perfiles que asisten a los programas de Máster, lo cierto es que la evidencia permite confirmar lo que en alguna medida se estableció en la introducción: Chile ha venido reconociendo explícitamente la relevancia del desarrollo de competencias en los lideres escolares, formando un numero relevante de profesionales en este universo de programas (cuadro 2).

Cuadro 2. Perfil de los estudiantes

\begin{tabular}{lcc}
\hline & FRECUENCIA & PORCENTAJE \\
\hline Profesores en búsqueda de perfeccionamiento general & 23 & 67,6 \\
Profesores en búsqueda de aumento salarial & 14 & 41,2 \\
Profesores que aspiran a ser directores & 30 & 88,2 \\
Directivos no directores, en búsqueda de perfeccionamiento & 21 & 61,8 \\
Directivos no directores, en búsqueda de aumento salarial & 5 & 14,7 \\
Directivos no directores, que aspiran a ser directores & 25 & 73,5 \\
Directores en búsqueda de perfeccionamiento general & 21 & 61,8 \\
\hline
\end{tabular}

Fuente: Elaboración propia en base a encuesta a encargados Programas de Máster 2017.

\subsection{Contenidos de los programas de formación en Chile}

La experiencia y literatura internacional es clara en relevar la importancia de que los programas de formación se orienten a contenidos conectados con las necesidades de los líderes educativos y que dichos contenidos les permitan a los directivos -en un escenario de múltiples demandas y de una historia con foco en los administrativo- potenciar su liderazgo pedagógico (Darling-Hammond et al., 2009; Dempster et al., 2019; Fluckinger, Lovett y Dempster, 2014). Nuestro estudio permite concluir que los programas de máster vigentes en Chile cubren una amplia variedad de contenidos y materias. Aunque no es posible distinguir un único ámbito que destaque por sobre otros en las mallas curriculares de los programas, se puede observar que los tópicos con mayor presencia corresponden a

\footnotetext{
${ }^{7}$ En cuanto a los nuevos estudiantes de estos programas especializados, este estudio permite afirmar que el promedio de ingreso del último año medido fue de 40 estudiantes por cada máster. Si se analizan las cifras agregadas, se puede afirmar que el $50 \%$ de los programas recibe 25 estudiantes o menos, mientras que otro $25 \%$ recibe más de 34 alumnos.
} 
los ámbitos de liderazgo educativo, planificación y gestión de centros, organización y clima escolar. En segundo término, se encuentran las cuestiones relativas a la gestión de recursos humanos, el diseño, evaluación y gestión de proyectos educativos y a la investigación educacional. En tercer lugar, aparecen los contenidos asociados a la planificación y evaluación curricular, gestión y administración de recursos y política educativa, y finalmente, encontramos contenidos asociados a la evaluación de aprendizajes y teoría de la educación ${ }^{8}$. Cabe señalar que todos los ámbitos son cubiertos por casi la totalidad de los programas, a excepción de los últimos dos señalados. En cualquier caso, puede apreciarse con claridad que hay un conjunto de áreas temáticas que son priorizadas por los programas y que configuran una parte importante de su sello actual.

$\mathrm{Al}$ realizar un ejercicio comparativo con los resultados del catastro del año 2010 descrito en la sección metodológica, se observan algunos cambios importantes durante el período de contraste. La evidencia muestra que las dimensiones referidas al liderazgo educativo, a la gestión organizacional y a la gestión de recursos humanos son las que presentan una mayor alza en su presencia relativa. Estos ámbitos son consistentes con la experiencia internacional y también con algunos referentes y políticas nacionales, que han dado mayor relevancia a las competencias de liderazgo en general y al foco de la dirección escolar en el desarrollo profesional docente en particular (MINEDUC, 2015; Pont, Nusche y Moorman, 2008; Weinstein y Muñoz, 2012). Por contrapartida, la dimensión propiamente teórica y normativa de la formación, representada en este caso por los ámbitos de teoría de la educación y política educativa, decaen sustantivamente, lo que pone de manifiesto que los ajustes realizados por los programas de formación han transitado hacia perspectivas de carácter más práctico y con foco en las capacidades de liderazgo de los profesionales de la educación. También es importante destacar el menor foco que los programas estarían poniendo en la evaluación de aprendizajes, lo que habla también de la especialización que están alcanzando los programas de formación de directivos escolares (cuadro 3).

Cuadro 3. Comparación contenidos de las mallas 2010-2017

\begin{tabular}{lccc}
\hline & $\mathbf{2 0 1 0}$ & $\mathbf{2 0 1 7}$ & $\begin{array}{c}\text { DIFERENCIA } \\
\text { PORCENTUAL }\end{array}$ \\
\hline Evaluación de aprendizajes & $74 \%$ & $55 \%$ & -19 \\
Investigación en educación & $80 \%$ & $82 \%$ & 2 \\
Diseño, evaluación y gestión de proyectos & $86 \%$ & $85 \%$ & -1 \\
Gestión y administración de recursos humanos & $71 \%$ & $88 \%$ & 17 \\
Gestión y administración de recursos financieros & $64 \%$ & $76 \%$ & 12 \\
Planificación y evaluación del currículo educativo & $78 \%$ & $76 \%$ & -2 \\
Organización y clima organizacional de establecimientos & $84 \%$ & $94 \%$ & 10 \\
$\quad$ educacionales & $90 \%$ & $94 \%$ & 4 \\
Gestión y gestión de centros educativos & $82 \%$ & $94 \%$ & 12 \\
Liderazgo educativo & $86 \%$ & $76 \%$ & -10 \\
Políticas y situación educacional en Chile & $55 \%$ & $35 \%$ & -20 \\
Teoría de la educación & & & \\
\hline Fuente: Elaboración propia en base a encuesta a encargados Programas de Máster, 2017 y 2010.
\end{tabular}

${ }^{8}$ La descripción detallada de dichos contenidos abarcados se encuentra en el cuadro A2 del anexo. 
Como confirmación de lo anterior, cuando se contrastan los "énfasis formativos" declarados por los distintos programas ${ }^{9}$ se observa que el ámbito de mayor preponderancia refiere a Liderazgo Educativo $^{10}$, mientras que el año 2010 este énfasis estaba puesto principalmente en el área de planificación y gestión de los centros educativos ${ }^{11}$. Los programas de formación han venido priorizando con mayor fuerza los contenidos directamente relacionados con las habilidades y desarrollo de competencias para el liderazgo escolar (cuadro 4).

Cuadro 4. Contenidos considerados como primera prioridad en las mallas. Comparación 2010-2017

\begin{tabular}{lcc}
\hline & $\mathbf{2 0 1 0}$ & $\mathbf{2 0 1 7}$ \\
\hline Liderazgo educativo & $6 \%$ & $69 \%$ \\
Planificación y gestión de centros educativos & $37 \%$ & $13 \%$ \\
Políticas y situación educacional en Chile & $4 \%$ & $6 \%$ \\
Planificación y evaluación del currículo educativo & $6 \%$ & $6 \%$ \\
Organización y clima organizacional de establecimientos & $4 \%$ & $3 \%$ \\
Investigación en educación & $12 \%$ & $3 \%$ \\
Diseño y evacuación de proyectos educativos & $12 \%$ & - \\
Evaluación de aprendizajes & $4 \%$ & - \\
Gestión y administración de RRHH & $4 \%$ & - \\
Gestión y administración de recursos financieros & $4 \%$ & - \\
Otro & $7 \%$ & - \\
\hline Total & $100 \%$ & $100 \%$ \\
\hline
\end{tabular}

Nota: “-“ Denota que el contenido no fue seleccionado como primera prioridad por ninguno de los encuestados.

Fuente: Elaboración propia en base a encuesta a encargados Programas de Máster, 2017 y 2010.

El estudio también levantó información sobre las principales competencias ${ }^{12}$ desarrolladas por los programas, de acuerdo a la opinión de sus encargados (cuadro 5). Los programas de máster se estarían concentrando, principalmente, en las competencias de organizar las funciones y recursos de los centros, de gestionar procesos de cambio, de establecer una visión compartida, de articular la teoría con la práctica, de propiciar un clima para el aprendizaje y de desplegar un liderazgo centrado en el proceso de enseñanza. Todo lo anterior es consistente con los contenidos priorizados por los programas, revisados anteriormente. Estas competencias son complementadas luego, en un segundo nivel de prioridad, con el desarrollo de habilidades asociadas a la comunicación e integridad ética de los líderes escolares, quedando en una posición inferior las competencias vinculadas a la promoción del desarrollo profesional docente y participación familiar. El análisis comparativo con el año 2010 muestra que los principales cambios se producen en el área de desarrollo de habilidades transversales asociadas a la comunicación, el desarrollo ético y la articulación teórico-práctica, todas cuales incrementan significativamente su

\footnotetext{
${ }^{9}$ Esto refiere a los contenidos curriculares considerados como prioritarios por los mismos programas.

${ }^{10}$ Definido en la encuesta como: "Visión y Misión del equipo directivo. Alineamiento del equipo en torno a metas comunes. Competencias para un liderazgo efectivo. Reconocimiento y estímulos para el desempeño de excelencia”.

${ }^{11}$ Definido en la encuesta como: "Formulación de un proyecto estratégico y de la estructura organizacional que lo soporta. Fundamentos de la planificación, ejecución y evaluación de los planes de acción derivados del proyecto estratégico de un centro educacional".

${ }^{12}$ Las competencias descritas se basan en la investigación "Formación y Entrenamiento de los Directores Escolares en Chile: situación actual, desafíos y propuestas de política”, realizada el año 2010 (Muñoz y Marfán, 2011).
} 
presencia. Estas cifras demuestran que los programas de formación le han ido dando mayor preponderancia a estas capacidades y competencias transversales, fundamentales para el desarrollo del liderazgo (Muñoz y Marfán, 2011).

Cuadro 5. Competencias desarrolladas (\% de programas que declara desarrollar estas competencias). Comparación 2010-2017

\begin{tabular}{lccc}
\hline & $\mathbf{2 0 1 0}$ & $\mathbf{2 0 1 7}$ & $\begin{array}{r}\text { DIFERENCIA } \\
\text { PORCENTUAL }\end{array}$ \\
\hline Organizar las funciones, estructuras y recursos & $87 \%$ & $91 \%$ & $4 \%$ \\
Gestionar procesos de cambio & $83 \%$ & $91 \%$ & $8 \%$ \\
Visión compartida & $83 \%$ & $91 \%$ & $8 \%$ \\
Articular teoría y práctica & $63 \%$ & $91 \%$ & $\mathbf{2 8 \%}$ \\
Propiciar un clima escolar favorable & $78 \%$ & $88 \%$ & $10 \%$ \\
Apoyo procesos de mejoramiento de la enseñanza & $74 \%$ & $82 \%$ & $8 \%$ \\
$\quad$ aprendizaje & $48 \%$ & $79 \%$ & $\mathbf{3 1 \%}$ \\
Expresión y comprensión de otros & $57 \%$ & $74 \%$ & $\mathbf{1 7 \%}$ \\
Valores de integridad, honestidad y respeto & $63 \%$ & $50 \%$ & $13 \%$ \\
Desarrollo profesional & $43 \%$ & $41 \%$ & $2 \%$ \\
Participación familiar & & \\
\hline
\end{tabular}

Nota: Los porcentajes destacados son aquellas diferencias porcentuales mayores al $15 \%$.

Fuente: Elaboración propia en base a encuesta a encargados Programas de Máster, 2017 y 2010.

En síntesis, puede afirmarse que este estudio da cuenta de trasformaciones curriculares importantes en los cerca de 45 programas de formación en liderazgo que actualmente se desarrollan en Chile. Al comparar con la situación del año 2010, se evidencia una mayor priorización curricular de áreas como los conocimientos específicos sobre liderazgo educativo, el acercamiento a herramientas de mejoramiento escolar y la gestión de recursos humanos. Este cambio, sin embargo, como se verá de aquí en adelante, convive con una marcada estabilidad de las principales metodologías utilizadas por los programas y la poca presencia de instancias prácticas de desarrollo profesional.

\subsection{Métodos predominantes y prácticas de evaluación de la formación}

La evidencia internacional sobre la preparación de directivos es contundente en demostrar que los programas que alcanzan un mayor efecto en las prácticas de sus egresados son aquellos que desarrollan experiencias situadas de formación, que permiten a los estudiantes aprender desde la propia práctica, así como también aplicar los conocimientos y habilidades desarrolladas en la formación. También sabemos que esas experiencias prácticas son más efectivas cuando están acompañadas de tutores o mentores, directivos o docentes con experiencia (Darling-Hammond et al., 2009; Huber, Skedsmo y Schwander, 2019; Orr, 2019; Pont, Nusche y Moorman, 2008; Schleicher, 2012).

Cuando se analizan las metodologías utilizadas por los programas chilenos en sus prácticas de enseñanza y de evaluación, se observa que las más utilizadas son básicamente las mismas que hace 7 años atrás: clases expositivas, talleres o trabajos grupales o individuales, estudios de caso, tesis y proyectos de grado. Una presencia mucho menor, incluso disminuyendo en el tiempo, tienen las prácticas o pasantías y los tutores en terreno (figura 2). En simple, la oferta formativa cuenta con escasa experiencias situadas y en consecuencia con pocas oportunidades para integrar teoría y práctica, a pesar de que una gran mayoría de los programas declara explícitamente que uno de sus objetivos principales es movilizar las prácticas de sus egresados. 


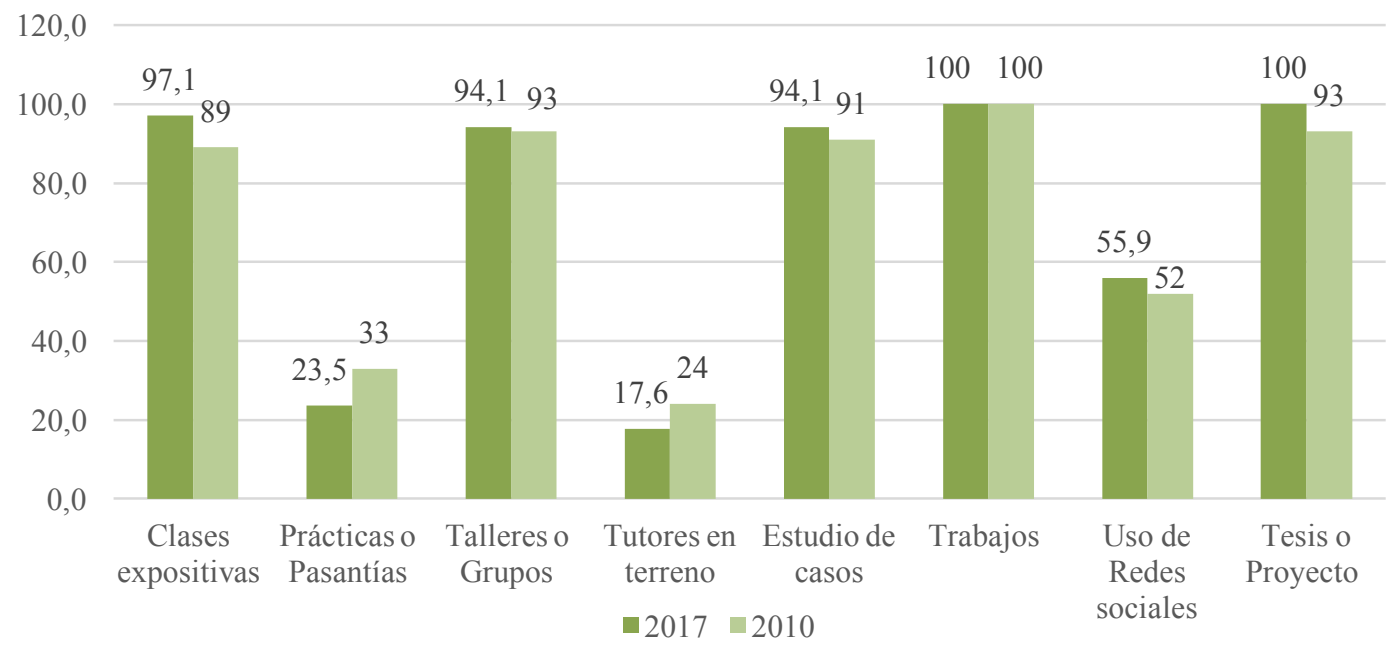

Figura 2. Comparación metodologías de enseñanza y evaluación 2010-1017 (\% de programas que declara utilizar esa metodología)

Fuente: Elaboración propia en base a encuesta a encargados Programas de Máster, 2017 y 2010.

Lo anterior se complementa con otro dato pesquisado por el estudio: el porcentaje de programas que poseen convenios con centros educativos para desarrollar prácticas (cuadro 6). La evidencia muestra que en los últimos 7 años los programas han avanzado en establecer convenios con establecimientos educacionales. Sin embargo, el porcentaje de programas que no lo posee sigue siendo significativamente mayor. Además, el número de programas que tiene convenios con centros educativos o que no los tienen, pero desarrolla acciones de formación práctica, es mayor para el año 2010 (50\%) que para el 2017 (44,1\%).

Cuadro 6. Convenios para prácticas. Comparación 2010-1017 (\% de programas que declara contar con convenios)

\begin{tabular}{cccc}
\hline Sí & No & $\begin{array}{c}\text { NO, PERO LOS ALUMNOS REALIZAN PRÁCTICAS EN } \\
\text { ESTABLECIMIENTO EDUCACIONALES SIN } \\
\text { CONVENIO }\end{array}$ \\
\hline 2010 & $9 \%$ & $50 \%$ & $41 \%$ \\
2017 & $35,3 \%$ & $55,9 \%$ & $8,8 \%$ \\
\hline
\end{tabular}

Fuente: Elaboración propia en base a encuesta a encargados Programas de Máster 2017.

Por otra parte, existe consenso también sobre la relevancia de que los programas de formación desarrollen procesos de mejora continua, que por cierto debieran considerar la evaluación de los efectos de la formación en las prácticas de los líderes (Fluckiger, Lovett, y Dempster, 2014; Orr, 2019; Wallace Foundation, 2016). Al analizar las acciones de evaluación y monitoreo que actualmente despliegan los programas de formación en Chile, se observa que se trata de un ámbito muy poco explorado o bien explorado de forma superficial y poco sistemática. Las evaluaciones realizadas por los programas tienden a centrarse en la apropiación de contenidos y la satisfacción con el proceso de formación, y muy poco en el desempeño efectivo de los egresados en sus puestos de trabajo y en los efectos que la formación tiene en la organización educativa. Las metodologías de evaluación utilizados se circunscriben a mecanismos tales como la autoevaluación o las pruebas de conocimiento. Los programas en general consideran muy poco lo que ocurre después de terminado el proceso de formación, tanto a nivel de indicadores de proceso 
como de resultado. Además, solo una proporción menor (cercano al 35\%) monitorea las trayectorias profesionales de sus egresados y, cuando se hace, en la mayoría de los casos este seguimiento no es permanente en el tiempo. A continuación, se presentan sintéticamente las estrategias de evaluación utilizadas por los programas y los momentos en los cuales se aplican dichas estrategias (cuadro 7).

Cuadro 7. Dispositivos de evaluación y temporalidades (\% de programas que declara implementar estas estrategias de evaluación)

\begin{tabular}{|c|c|c|c|c|c|}
\hline ESTRATEGIAS & $\begin{array}{c}\text { AL } \\
\text { INICIO }\end{array}$ & $\begin{array}{l}\text { DURANTE LA } \\
\text { FORMACIÓN }\end{array}$ & $\begin{array}{l}\text { AL FINALIZAR } \\
\text { LA FORMACIÓN }\end{array}$ & $\begin{array}{l}\text { DESPUÉS DE } \\
\text { FINALIZAR EL } \\
\text { PROGRAMA }\end{array}$ & $\begin{array}{c}\text { No SE } \\
\text { REALIZA }\end{array}$ \\
\hline $\begin{array}{l}\text { Observación de prácticas en } \\
\text { espacios laborales de } \\
\text { estudiantes y/ o }\end{array}$ & 17,6 & 26,5 & 5,9 & 2,9 & 47,1 \\
\hline $\begin{array}{l}\text { Autoevaluación de } \\
\text { aprendizajes por parte de }\end{array}$ & 11,8 & 76,5 & 14,7 & 5,9 & 8,8 \\
\hline $\begin{array}{l}\text { Evaluación de aprendizajes } \\
\text { regulares (pruebas, }\end{array}$ & 14,7 & 88,2 & 41,2 & 2,9 & $\mathrm{O}$ \\
\hline $\begin{array}{l}\text { Encuesta de satisfacción a } \\
\text { estudiantes o egresados }\end{array}$ & 5,9 & 55,9 & 29,4 & 20,6 & 5,9 \\
\hline $\begin{array}{l}\text { Consulta a comunidades } \\
\text { escolares (equipos } \\
\text { directivos, profesores, }\end{array}$ & $\mathrm{O}$ & 5,9 & 2,9 & 35,3 & 47,1 \\
\hline $\begin{array}{l}\text { Análisis de indicadores } \\
\text { externos (mejora en } \\
\text { procesos o indicadores de } \\
\text { establecimientos } \\
\text { educativos) }\end{array}$ & 2,9 & 26,5 & 5,9 & 2,9 & 64,7 \\
\hline $\begin{array}{l}\text { Análisis de indicadores } \\
\text { individuales (trayectorias } \\
\text { laborales, trayectorias } \\
\text { educativas, mejora } \\
\text { remuneraciones de los } \\
\text { estudiantes o egresados) }\end{array}$ & 8,8 & 17,6 & 2,9 & 20,6 & 52,9 \\
\hline
\end{tabular}

Nota: Los porcentajes destacados representan las estrategias de evaluación donde más del 45\% de los programas declara no realizarlas.

Fuente: Elaboración propia en base a encuesta a encargados Programas de Máster 2017.

Como síntesis de esta sección, puede plantearse que la formación de directivos en Chile está basada en un conjunto de métodos de trabajo esencialmente teóricos, academicistas y con escasa presencia de oportunidades de aprendizaje prácticas. Estas características además no se han modificado sustantivamente en los últimos años, a pesar de la abundante evidencia respecto a la formación de calidad en esta área. Este estancamiento metodológico convive con una precaria evaluación de los programas, que no permite generar evidencia sustantiva sobre los efectos reales de los mismos, lo que conspira contra el objetivo de mejorar continuamente estas acciones formativas.

\section{Discusión}

El contexto general de cambios que enfrenta el sistema escolar chileno desafía fuertemente a la función directiva. Si bien hace ya algunos años se ha venido develando la necesidad de fortalecer el liderazgo pedagógico de los directivos escolares, la implementación gradual 
de las transformaciones que actualmente vive la educación chilena tensiona a la función directiva y la invitan a traducir cada uno de los cambios en curso en oportunidades concretas de mejoramiento del trabajo de sus unidades educativas (Weinstein, Muñoz y Rivero, 2018). Lo anterior obliga a desarrollar y potenciar las capacidades de los líderes educacionales, lo que a su vez implica impulsar una agenda de calidad de su preparación. Esto es doblemente relevante en un escenario de proliferación de programas de formación de líderes (con la consecuente inversión pública y privada) y de poca evidencia sobre los resultados que esta formación tiene en el país y la región.

Este articulo ha intentado contribuir en esta área, por medio una caracterización de los programas nacionales vigentes de máster especializados en esta área y una comparación de dichas características con una observación inicial realizada en el año 2010. La evidencia recopilada permite concluir que, además de una expansión evidente de la oferta formativa dirigida a los directivos escolares, en Chile se ha experimentado en los últimos años un importante cambio curricular, que se ha traducido en una mayor priorización de conocimientos y habilidades como la teoría y práctica del liderazgo educativo, herramientas para el mejoramiento escolar o la gestión del desarrollo profesional docente. Este interesante cambio convive, sin embargo, con un evidente estancamiento a nivel metodológico: sigue predominando un modelo formativo esencialmente teórico y carente de instancias prácticas de desarrollo profesional, lo que limita las posibilidades de que esta formación logre impactar sustantivamente en el aprendizaje y desempeño de los líderes escolares.

La investigación, y su diálogo con la literatura internacional especializada, permite también proyectar algunos desafíos clave para la formación de directivos en Chile, que son también extensibles a parte importante de América Latina. El reto pareciera evidente: si bien se ha ido consolidando la disponibilidad de oferta formativa y se han ido ajustando algunos de los contenidos de los programas, avanzar en la calidad de esta formación supondrá acciones de política decididas en este ámbito.

En primer lugar, pareciera fundamental contar con marcos de actuación o estándares directamente dirigidos a orientar la formación de los líderes. La variedad de tareas y responsabilidades que hoy se encomienda a los directores hace indispensable una clara delimitación de lo que se espera de ellos y también de su preparación, sobre todo si se considera que la formación en liderazgo debe ser un acto de permanente equilibrio entre las necesidades del sistema educativo y las de los propios directivos (Dempster et al., 2019). Esto además permitiría avanzar en una segunda dimensión de políticas: la regulación y orientación de la formación. Hoy resulta riesgoso apostar solamente por el crecimiento de la oferta formativa sin previamente definir cuáles son las exigencias y estándares de calidad que los programas deben cumplir, sobre todo en contextos de amplia participación de instituciones colaboradoras públicas y privadas. Un piso básico al que debiera apuntarse consiste en desarrollar un sistema de certificación de programas que garantice que los directores pasen por espacios formativos que efectivamente sean útiles y aporten al desafío de mejorar la calidad de los aprendizajes.

En tercer término, como demuestran los datos que este artículo ha presentado, también es evidente que una política de formación de directores debe tener la capacidad de distinguir adecuadamente las distintas fases de preparación que requieren los líderes, lo que además debe estar estrechamente relacionado con las fases de la carrera directiva, en general inexistentes todavía en nuestras latitudes, que se decida impulsar. Diferenciando 
al menos las fases de formación inicial, de inducción y continua (o de desarrollo permanente), las políticas debieran avanzar en establecer las expectativas formativas para cada una de ellas. En cuarto lugar, es importante que la formación contemple diseños de evaluación que permitan monitorear y legitimar las acciones formativas que se desarrollen. Hoy ésta es una debilidad central de la formación que se ha estado entregando en Chile, pero también un desafío a nivel mundial. Avanzar en una evaluación y seguimiento de la formación puede ser un aspecto diferenciador de las políticas formativas en América Latina.

Todo lo anterior, por cierto, supone una participación y compromiso activo del estado, que debe liderar la fijación de las expectativas formativas y también la generación de marcos regulatorios que permitan garantizar la calidad de la formación. Esto, sin embargo, debiera ser complementado con una política de innovación y apoyo a la creación de nueva oferta o mejoramiento de la que existe, que permita impulsar las mejores prácticas internacionales en este ámbito: foco en la reflexión y resolución de problemas de práctica, formación situada y un claro componente aplicado, la existencia de convenios de trabajo entre los programas y centros educativos, implementación de mentorías y sistemas de acompañamiento a los estudiantes, evaluación permanente de sus procesos y resultados, etc.

Construir una política y práctica de formación de directivos a la altura de lo que nuestros países requieren supone también una nueva base empírica de conocimientos que permita orientar la mejora continua de la preparación de los líderes (Young, 2019). Prioridades en este ámbito debieran ser la realización de diagnósticos certeros sobre las necesidades de formación de los líderes en distintos contextos, el estudio evaluativo permanente de los procesos de formación vigentes, y sobre todo la investigación sobre los efectos que tienen distintas modalidades de formación en las capacidades, prácticas y trayectorias de los líderes.

\section{Agradecimientos}

Este artículo se elaboró en el marco de los proyectos de investigación del Centro de Desarrollo de Liderazgo Educativo (CEDLE), alianza de universidades apoyada y financiada por el Ministerio de Educación de Chile. Esta publicación particular se enmarca en el proyecto "Formación de directivos en Chile y efectos en sus prácticas: Hacia un modelo de evaluación del desarrollo de capacidades en los líderes escolares", desarrollado durante el año 2017.

\section{Referencias}

Aas, M. y Fluckiger, B. (2016). The role of a group coach in the professional learning of school leaders. Coaching: An International Journal of Theory, Research and Practice, 9(1), 38-52. https://doi.org/10.1080/17521882.2016.1143022

Bellei, C. (2018). Nueva educación pública: Contexto, contenidos y perspectivas de la desmunicipalización. Santiago de Chile: LOM Ediciones.

Bush, T. (2019). Cultivo del liderazgo educativo: Principios fundamentales. En J. Weinstein y G. Muñoz (Eds.), Cómo cultivar el liderazgo educativo: Trece miradas (pp. 23-34). Santiago de Chile: Ediciones Universidad Diego Portales. 
Cobb, C. D., Weiner, J. M. y Gonzales, R. (2016). Historical trends and patterns in the scholarship on leadership preparation. En M. Young y G. Crow (Eds.), Handbook of research on the education of school leaders (pp. 29-53). Nueva York, NY: Routledge.

Darling-Hammond, L., Meyerson, D., LaPointe, M. y Orr, M. T. (2009). Preparing principals for a changing world: Lessons from effective school leadership programs. San Francisco, CA: John Wiley \& Sons. https://doi.org/10.1002/9781118269329

Dempster, N., Lovett, S., Fluckiger, B. y Johnson, G. (2019). Desarrollo profesional de directivos escolares: Un acto de permanente equilibrio. En J. Weinstein y G. Muñoz (Eds.), Cómo cultivar el liderazgo educativo: Trece miradas (pp. 241-273). Santiago de Chile: Ediciones Universidad Diego Portales.

Donoso, S., Benavides, N., Cancino, V., Castro, M. y López, L. (2012). Análisis crítico de las políticas de formación de directivos escolares en Chile: 1980-2010. Revista Brasileira de Educação, 17(49), 223-240. https://doi.org/10.1590/S1413-24782012000100008

Fluckiger, B., Lovett, S. y Dempster, N. (2014). Judging the quality of school leadership learning programs: An international search. Professional Development in Education, 40(4), 561-575. https://doi.org/10.1080/19415257.2014.902861

FOCUS. (2016). Estudio de caracterización de los equipos directivos escolares de establecimientos educacionales subvencionados urbanos de Chile. Santiago de Chile: FOCUS.

Gómez-Delgado, A. M., Oliva-Rodríguez, N. y López-Yáñez, J. (2014). La indefinición del modelo español de formación de líderes escolares. REICE. Revista Iberoamericana sobre Calidad, Eficacia y Cambio en Educación, 12(5), 135-150.

Hackmann, D. G. y McCarthy, M. M. (2011). At a crossroads: The educational leadership professoriate in the 21 st century. Charlotte, NC: Information Age.

Hitt, D. y Tucker, P. (2016). Systematic review of key leader practices found to influence student achievement: A unified framework. Review of Educational Research, 86(2), 531-569. https://doi.org/10.3102/0034654315614911

Huber, S. (2006). School leader development: Current trends from a global perspective. Schweizerische Zeitschrift für Bildungswissenschaften, 28, 37-56.

Huber, S., Skedsmo, G. y Schwander, M. (2019). Cómo aprenden los directivos y fortalecen su reflexión professional en tanto líderes pedagógicos. En J. Weinstein y G. Muñoz (Eds.), Cómo cultivar el liderazgo educativo: Trece miradas (pp. 200-240). Santiago de Chile: Ediciones Universidad Diego Portales.

Jackson, B. y Kelley, C. (2002). Exceptional and innovative programs in educational leadership. Educational Administration Quarterly, 38(2), 192-212. https://doi.org/10.1177/0013161X02382005

Leithwood, K. y Jantzi, D. (2000). The effects of different sources of leadership on student engagement in school. En K. Riley y K. S. Louis (Eds.), Leadership for change and school reform: International perspectives (pp. 50-66). Nueva York, NY: Routledge.

Leithwood, K. y Jantzi, D. (2005). A review of transformational school leadership research 19962005. Leadership and Policy in Schools, 4(3), 177-199. https://doi.org/10.1080/15700760500244769

Leithwood, K., Harris, A. y Hopkins, D. (2008). Seven strong claims about successful school leadership. School Leadership and Management, 28(1), 27-42. https://doi.org/10.1080/13632430701800060

Marzano, R., Waters, T. y McNulty, B. (2005). School leadership that works: From research to results. Alexandria, VA: ASCD. 
MINEDUC. (2015). Marco para la buena dirección y el liderazgo escolar. Santiago de Chile: Ministerio de Educación.

Murillo, F. J. (2006). Una dirección escolar para el cambio: Del liderazgo transformacional al liderazgo distribuido. REICE. Revista Iberoamericana sobre Calidad, Eficacia y Cambio en Educación, 4(4e), 11-24.

Murillo, F. J. (2012). La dirección escolar en Chile: Una visión en el contexto de América Latina. En J. Weinstein y G. Muñoz (Eds.). Qué sabemos sobre los directores de escuela en Chile (pp. 1940). Santiago: CEPPE y Fundación Chile.

Muñoz, G. (2018). Estudio exploratorio sobre modelos internacionales de formación de directores y supervisores: un análisis en clave comparada. Buenos Aires: IIPE-UNESCO.

Muñoz, G. y Marfán, J. (2011). Competencias y formación para un liderazgo escolar efectivo en Chile. Pensamiento Educativo. Revista de Investigación Educacional Latinoamericana 48(1), 6380. https://doi.org/10.7764/PEL.48.1.2011.5

Oliva-Rodríguez, N. y López-Yáñez, J. (2019). Autoaprendizaje en pequeños grupos para la formación de directores escolares. Análisis de un programa piloto. REICE. Revista Iberoamericana sobre Calidad, Eficacia y Cambio en Educación, 17(1), 55-71. https://doi.org/10.15366/reice2019.17.1.004

Oplatka, I. (2017). El surgimiento de la gestión educativa como campo de estudio en América Latina. En J. Weinstein (Ed.), Liderazgo educativo en la escuela: Nuevas miradas (pp. 253-276). Santiago de Chile: Ediciones Universidad Diego Portales.

Orr, M. y Orphanos, S. (2011). How graduate-level preparation influences the effectiveness of school leaders: A comparison of the outcomes of exemplary and conventional leadership preparation programs for principals. Educational Administration Quarterly, 47(1), 18-70. https://doi.org/10.1177/0011000010378610

Orphanos, S. y Orr, M. T. (2014). Learning leadership matters: The influence of innovative school leadership preparation on teachers' experiences and outcomes. Educational Management Administration \& Leadership, 42(5), 680-700. https://doi.org/10.1177/1741143213502187

Poggi, M. (2019). Liderazgo escolar y formación directiva: Reflexiones desde América Latina. En En J. Weinstein y G. Muñoz (Eds.), Cómo cultivar el liderazgo educativo: Trece miradas (pp. 109-139). Santiago de Chile: Ediciones Universidad Diego Portales.

Pont, B., Nusche, D. y Moorman, H. (2008). Improving school leadership. Practice and policy. París: OECD.

Qian, H., Walker, A. y Bryant, D. (2017). Global trends and issues in the development of educational leaders. En M. Young y G. Crow (Eds.), Handbook of research on the education of school leaders (pp. 53-73). Nueva York, NY: Routledge.

Reyes-Guerra, D. y Barnett, B. (2017). Clinical practice in educational leadership. En M. Young y G. Crow (Eds.), Handbook of research on the education of school leaders (pp. 229-261). Nueva York, NY: Routledge.

Rincón-Gallardo, S. (2019). Las redes escolares como entornos de aprendizaje para los líderes educativos. En J. Weinstein y G. Muñoz (Eds.), Cómo cultivar el liderazgo educativo: Trece miradas (pp. 355-388). Santiago de Chile: Ediciones Universidad Diego Portales.

Robinson, V., Lloyd, C. y Rowe, K. (2008). The impact of leadership on student outcomes: An analysis of the differential effects of leadership types. Educational Administration Quarterly, 44(5), 635-674. https://doi.org/10.1177/0013161X08321509

Schleicher, A. (Ed.) (2012). Preparing teachers and developing school leaders for the 21 st century: Lessons from around the world. París: OECD. 
Slater, C., García, J. M. y Mentz, C. (2019). Liderazgo en los directivos principiantes: Hallazgos de un estudio internacional comparado. En J. Weinstein y G. Muñoz (Eds.), Cómo cultivar el liderazgo educativo: Trece miradas (pp. 299-322). Santiago de Chile: Ediciones Universidad Diego Portales.

Treviño, E. (2018). Diagnóstico del sistema escolar: Las reformas educativas 2014-2017. En I. Sanchez (Ed.), Ideas en educación: Reflexiones y propuestas desde la UC (pp. 133-165). Santiago de Chile: Ediciones UC.

Wallace Foundation. (2016). Improving university principal preparation programs: Five themes from the field. Nueva York, NY: Wallace Foundation.

Weinstein, J. y Muñoz, G. (2012). ¿Qué sabemos sobre los directores de escuela en Chile? Santiago de Chile: CEPPE y Fundación Chile.

Weinstein, J., Azar, A. y Flessa, J. (2018). An ineffective preparation? The scarce effect in primary school principals' practices of school leadership preparation and training in seven countries in Latin America. Educational Management Administration E Leadership, 46(2), 226-257. https://doi.org/10.1177/1741143217728083

Weinstein, J., Muñoz, G. y Rivero, R. (2018). Los directivos escolares como informantes cualificados de las políticas educativas. Sus opiniones bajo el gobierno de Michelle Bachelet en Chile (2014-2017). REICE. Revista Iberoamericana sobre Calidad, Eficacia y Cambio en Educación, 16(3), 5-27. https://doi.org/10.15366/reice2018.16.3.001

Weinstein, J., Cuellar, C., Hernández, M. y Flessa, J. (2015). Experiencias innovadoras y renovación de la formación directiva latinoamericana. Revista Iberoamericana de Educación, 69, 23-46.

Young, M. (2019). Desarrollo y formación en liderazgo educativo: Historia, desarrollo y prácticas contemporáneas en los Estados Unidos. En J. Weinstein y G. Muñoz (Eds.), Cómo cultivar el liderazgo educativo: Trece miradas (pp. 35-83). Santiago de Chile: Ediciones Universidad Diego Portales.

Young, M. D., Crow, G., Murphy, J. y Ogawa, R. (2009). The handbook of research on the education of school leaders. Nueva York, NY: Routledge. https://doi.org/10.4324/9780203878866 


\section{Anexos}

Cuadro A 1. Catastro programas de formación en liderazgo escolar año 2017

\begin{tabular}{|c|c|c|c|}
\hline UNIVERSIDAD & SEDE & TitUlación & MODALIDAD \\
\hline \multirow{2}{*}{$\begin{array}{l}\text { Pontificia } \\
\text { Universidad } \\
\text { Catolica de Chile }\end{array}$} & \multirow{2}{*}{ Santiago } & $\begin{array}{l}\text { Magíster en ciencias de la educación } \\
\text { mención dirección y liderazgo } \\
\text { educacional (Regular) }\end{array}$ & Presencial \\
\hline & & $\begin{array}{l}\text { Magíster en ciencias de la educación } \\
\text { mención dirección y liderazgo } \\
\text { educacional (Ejecutivo) }\end{array}$ & Semi presencial \\
\hline $\begin{array}{l}\text { Universidad de } \\
\text { Concepcion }\end{array}$ & Concepción & $\begin{array}{l}\text { Magister en gestión y liderazgo } \\
\text { educativo }\end{array}$ & Presencial \\
\hline $\begin{array}{l}\text { Universidad del } \\
\text { Bio-Bio }\end{array}$ & Chillán & $\begin{array}{l}\text { Magíster en liderazgo y gestión de } \\
\text { establecimientos educacionales }\end{array}$ & Presencial \\
\hline Universidad Mayor & $\begin{array}{l}\text { Santiago } \\
\text { Temuco }\end{array}$ & $\begin{array}{l}\text { Magister en gestión directiva de } \\
\text { excelencia }\end{array}$ & Presencial \\
\hline $\begin{array}{l}\text { Universidad } \\
\text { Central }\end{array}$ & $\begin{array}{l}\text { Santiago } \\
\text { La serena }\end{array}$ & $\begin{array}{l}\text { Magister en gestión y liderazgo } \\
\text { educacional }\end{array}$ & Presencial \\
\hline $\begin{array}{l}\text { Universidad San } \\
\text { Sebastián }\end{array}$ & $\begin{array}{l}\text { Bellavista } \\
\text { Concepción } \\
\text { Osorno } \\
\text { Puerto Montt } \\
\text { Rancagua } \\
\text { Valdivia } \\
\end{array}$ & $\begin{array}{l}\text { Magíster en alta dirección y gestión de } \\
\text { instituciones educacionales }\end{array}$ & Presencial \\
\hline $\begin{array}{l}\text { Universidad de } \\
\text { Aconcagua }\end{array}$ & Santiago & $\begin{array}{l}\text { Magister en educación con mención: } \\
\text { Gestión educacional }\end{array}$ & Online \\
\hline $\begin{array}{l}\text { Universidad } \\
\text { Andres Bello }\end{array}$ & $\begin{array}{l}\text { Santiago } \\
\text { Concepción }\end{array}$ & $\begin{array}{l}\text { Magister en dirección y liderazgo para } \\
\text { la gestión educacional }\end{array}$ & $\begin{array}{l}\text { Presencial con } \\
\text { opción a } \\
\text { distancia }\end{array}$ \\
\hline $\begin{array}{l}\text { Universidad del } \\
\text { Desarrollo } \\
\end{array}$ & Santiago & Magister en dirección y gestión escolar & Semi presencial \\
\hline $\begin{array}{l}\text { Universidad de } \\
\text { Playa Ancha }\end{array}$ & Viña del mar & $\begin{array}{l}\text { Magíster en administración educacional } \\
\text { mención gestión en sistemas educativos }\end{array}$ & Semi presencial \\
\hline $\begin{array}{l}\text { Universidad Santo } \\
\text { Tomás }\end{array}$ & $\begin{array}{l}\text { Iquique } \\
\text { La serena } \\
\text { Osorno } \\
\text { Puerto montt } \\
\text { Los ángeles } \\
\text { Temuco } \\
\end{array}$ & $\begin{array}{l}\text { Magíster en educación con mención en } \\
\text { gestión de centros educacionales }\end{array}$ & Presencial \\
\hline $\begin{array}{l}\text { Universidad } \\
\text { Católica de } \\
\text { Temuco } \\
\end{array}$ & Temuco & Magíster en gestión escolar & Semi presencial \\
\hline $\begin{array}{l}\text { Universidad de } \\
\text { Santiago } \\
\end{array}$ & Santiago & $\begin{array}{l}\text { Magíster en educación mención en } \\
\text { gestión educacional }\end{array}$ & Presencial \\
\hline $\begin{array}{l}\text { Universidad de } \\
\text { Arte y Ciencias } \\
\text { Sociales } \\
\end{array}$ & Santiago & $\begin{array}{l}\text { Magíster en educación mención en } \\
\text { gestión educacional (a distancia) }\end{array}$ & Online \\
\hline $\begin{array}{l}\text { Universidad } \\
\text { Alberto Hurtado } \\
\end{array}$ & Santiago & $\begin{array}{l}\text { Magíster en gestión y dirección } \\
\text { educacional }\end{array}$ & Presencial \\
\hline $\begin{array}{l}\text { Universidad de } \\
\text { Talca }\end{array}$ & Talca & $\begin{array}{l}\text { Magíster en política y gestión } \\
\text { educacional }\end{array}$ & Presencial \\
\hline $\begin{array}{l}\text { Universidad de } \\
\text { Tarapacá }\end{array}$ & Arica & $\begin{array}{l}\text { Magíster en educación con mención en } \\
\text { administración educacional o currículo }\end{array}$ & Presencial \\
\hline
\end{tabular}




\begin{tabular}{|c|c|c|c|}
\hline $\begin{array}{l}\text { Universidad los } \\
\text { Andes }\end{array}$ & Santiago & Magíster en dirección y gestión escolar & Presencial \\
\hline $\begin{array}{l}\text { Universidad } \\
\text { Adventista de } \\
\text { Chile }\end{array}$ & Chillán & $\begin{array}{l}\text { Magíster en educación mención en } \\
\text { gestión educativa }\end{array}$ & Semi presencial \\
\hline $\begin{array}{l}\text { Universidad } \\
\text { Católica Silva } \\
\text { Henríquez } \\
\end{array}$ & Santiago & $\begin{array}{l}\text { Magíster en educación mención en } \\
\text { gestión y liderazgo pedagógico }\end{array}$ & Presencial \\
\hline $\begin{array}{l}\text { Universidad } \\
\text { Católica del } \\
\text { Maule } \\
\end{array}$ & $\begin{array}{l}\text { Curicó } \\
\text { Talca }\end{array}$ & $\begin{array}{l}\text { Magíster en educación mención } \\
\text { currículum y administración }\end{array}$ & Presencial \\
\hline $\begin{array}{l}\text { Universidad } \\
\text { Metropolitana de } \\
\text { Ciencias de la } \\
\text { Educación }\end{array}$ & Santiago & $\begin{array}{l}\text { Magíster en educación con mención en } \\
\text { gestión educacional }\end{array}$ & Presencial \\
\hline $\begin{array}{l}\text { Universidad Miguel } \\
\text { de Cervantes }\end{array}$ & Santiago & $\begin{array}{l}\text { Magíster en educación mención gestión } \\
\text { de calidad }\end{array}$ & A distancia \\
\hline $\begin{array}{l}\text { Universidad } \\
\text { Academia de } \\
\text { Humanismo } \\
\text { Cristiano }\end{array}$ & Santiago & $\begin{array}{l}\text { Magister en educación mención } \\
\text { liderazgo pedagógico }\end{array}$ & Presencial \\
\hline
\end{tabular}

Cuadro A2. Contenidos desarrollados por los programas de formación

\begin{tabular}{|c|c|}
\hline CONTENIDOS & DESCRIPCIÓN \\
\hline Teoría de la Educación & Fundamentos teóricos de la educación y del aprendizaje \\
\hline $\begin{array}{l}\text { Políticas y Situación } \\
\text { Educacional en Chile }\end{array}$ & $\begin{array}{l}\text { Marco jurídico del sistema educacional chileno. Políticas públicas } \\
\text { de Educación en Chile y sus desafíos }\end{array}$ \\
\hline Liderazgo educativo & $\begin{array}{l}\text { Visión y Misión del equipo directivo. Alineamiento del equipo en } \\
\text { torno a metas comunes. Competencias para un liderazgo } \\
\text { efectivo. Reconocimiento y estímulos para el desempeño de } \\
\text { excelencia }\end{array}$ \\
\hline $\begin{array}{l}\text { Planificación y gestión de } \\
\text { centros educativos }\end{array}$ & $\begin{array}{l}\text { Formulación de un proyecto estratégico y de la estructura } \\
\text { organizacional que lo soporta. Fundamentos de la planificación, } \\
\text { ejecución y evaluación de los planes de acción derivados del } \\
\text { proyecto estratégico de un centro educacional }\end{array}$ \\
\hline $\begin{array}{l}\text { Organización y Clima } \\
\text { Organizacional de } \\
\text { establecimientos } \\
\text { educacionales }\end{array}$ & $\begin{array}{l}\text { Naturaleza de la Organización Educacional. Diagnóstico y } \\
\text { análisis organizacional. Gestión de la cultura, comunicaciones } \\
\text { internas, clima organizacional y de la convivencia escolar. El } \\
\text { conflicto como fuente de aprendizaje }\end{array}$ \\
\hline $\begin{array}{l}\text { Planificación y Evaluación } \\
\text { del currículo educativo }\end{array}$ & $\begin{array}{l}\text { Formulación de objetivos educacionales derivados del Proyecto } \\
\text { Educativo. Diseño, implementación y evaluación de la malla } \\
\text { curricular. Evaluación de procesos pedagógicos en el aula }\end{array}$ \\
\hline $\begin{array}{l}\text { Gestión y Administración de } \\
\text { Recursos Financieros }\end{array}$ & $\begin{array}{l}\text { Gestión de las finanzas, del presupuesto y de la contabilidad de } \\
\text { un establecimiento educacional. Determinación de flujos de } \\
\text { cajas. Concepto de una estrategia competitiva y definición del } \\
\text { posicionamiento deseado }\end{array}$ \\
\hline $\begin{array}{l}\text { Gestión y Administración de } \\
\text { Recursos Humanos }\end{array}$ & $\begin{array}{l}\text { Administración y gestión de recursos humanos; selección, } \\
\text { contratación, evaluación y desarrollo del desempeño del } \\
\text { personal del establecimiento educacional. Administración por } \\
\text { competencias. Sistemas de incentivos y compensaciones }\end{array}$ \\
\hline $\begin{array}{l}\text { Diseño, evaluación y gestión } \\
\text { de proyectos educativos }\end{array}$ & $\begin{array}{l}\text { Formulación del problema y objetivos del proyecto. Definición } \\
\text { de recursos físicos, económicos y humanos del proyecto. } \\
\text { Técnicas de evaluaciones sociales y económicas de un proyecto) }\end{array}$ \\
\hline
\end{tabular}


Formulación del problema de investigación. Técnicas de Investigación en Educación investigación educacional. Análisis e interpretación de datos. Comunicación de los datos

Herramientas de evaluación en educación, evaluaciones

Evaluación de aprendizajes nacionales e internacionales, evaluación para el aprendizaje en la escuela y aula

Fuente: Elaboración propia a partir de Muñoz y Marfán (2011).

\section{Breve CV de los autores}

\section{Gonzalo Muñoz}

Sociólogo y Magíster en Sociología de la Universidad Católica de Chile. Académico de la Facultad de Educación y director del Magíster en Liderazgo y Gestión Educativa de la Universidad Diego Portales. Ha publicado varios libros y artículos en sus áreas de especialidad: políticas educacionales, efectividad y mejoramiento escolar, y liderazgo educativo. Ha sido consultor en proyectos del BID, Banco Mundial, OECD y UNESCO, y ha colaborado con procesos de cambio educativo en países como Uruguay, Paraguay, Panamá y Honduras. ORCID ID: https://orcid.org/0000-0001-7219-0841. Email: gonzalo.munozs@mail.udp.cl

\section{Josefina Amenábar}

Socióloga de la Universidad Católica de Chile. Asistente de investigación del Centro de Desarrollo y Liderazgo Educativo (CEDLE) y de la Facultad de Educación de la Universidad Diego Portales. Anteriormente participó en estudios para el Programa de las Naciones Unidas para el Desarrollo (PNUD) y el Centro de Perfeccionamiento, Experimentación e Investigaciones Pedagógicas (CPEIP) del Ministerio de Educación. ORCID ID: https://orcid.org/0000-0003-3440-0419. Email: josefina.amenabarg@gmail.com

\section{María José Valdebenito}

Socióloga, Magister en Política y Gobierno y candidata a doctora en Ciencias Sociales de la Universidad de Buenos Aires. Se ha dedicado a la investigación y docencia en la Universidad Alberto Hurtado por más de 10 años, estando a cargo del equipo de estudios y proyectos del Centro de Investigación y Desarrollo de la Educación, CIDE. Sus intereses de investigación se vinculan al área Educación y Trabajo, desarrollando varias investigaciones y publicaciones relacionadas a trayectorias educativas-laborales de jóvenes y adultos. ORCID ID: https://orcid.org/0000-0002-9231-188X. Email: mavaldeb@uahurtado.cl 